Estudios sobre armas antiguas, arte militar $\mathrm{y}$ vida cultural en oriente y occidente

XXXVIII (2018), pp. 67-87

ISSN: 0436-029X

https://doi.org/10.3989/gladius.2018.05

\title{
LAS CAMPAÑAS EN MESIA DURANTE LA PRIMERA GUERRA DÁCICA DE TRAJANO (101-102 D. C.): LA ÚLTIMA TENTATIVA EXPANSIONISTA DEL ESTADO DACIO
}

\author{
THE MOESIAN CAMPAIGNS DURING TRAJAN'S FIRST DACIAN WAR (101-102 AD): THE \\ LAST EXPANSIONIST ATTEMPT OF THE DACIAN STATE
}

POR

\author{
DAVID SORIa MOLInA*
}

\section{RESUMEN - ABSTRACT}

Las operaciones desarrolladas en Mesia Inferior en los meses de verano y otoño del año 101 d. C., durante la primera guerra dácica de Trajano, supusieron la última gran manifestación de las ambiciones expansionistas del Estado dacio en la Europa danubiana y a punto estuvieron de inclinar seriamente contra de Roma la balanza de la contienda. La contundente derrota sufrida por los dacios y sus aliados a manos de Trajano en Mesia Inferior, por contra, sentenció el resultado de la guerra y selló indirectamente el destino final del reino dacio. A lo largo de estas páginas abordamos un detallado análisis de estas operaciones, su alcance y sus implicaciones estratégicas, mediante una concienzuda revisión de las fuentes literarias, epigráficas e iconográficas, combinado con un apropiado conocimiento del escenario del conflicto, sus características y su impacto sobre el desarrollo de la campaña.

The operations carried out in Moesia Inferior in summer and autumn of 101 AD, during Trajan's first Dacian War, supposed the last great display of the Dacian State's expansionist ambitions over Danubian Europe and were about to tilt against Rome the balance of the conflict. The overwhelming defeat suffered by the Dacians and their allies at Trajan's hands on Moesia Inferior sentenced the result of the war and indirectly sealed the fate of the Dacian kingdom. Throughout these pages we are going to tackle a detailed analysis of these operations, its scope and its strategic implications by means of a thorough revision of the literary, epigraphic and iconographic sources, combined with a proper knowledge of the conflict's scenario, its characteristics and its impact over the course of the campaign.

\section{Palabras Clave - Keywords}

Dacia; Trajano; guerras dácicas; Decébalo; sármatas roxolanos; bastarnos; Tropaeum Traiani; Danubio; Mar Negro; corona classica; guerra naval.

Dacia; Trajan; Dacian Wars; Decebalus; Roxolani; Bastarnae; Troapeum Traiani; Danube; Black Sea; corona classica; Naval Warfare.

\section{Cómo CITAR ESTE ARTículo / CitATION}

Soria Molina, D. (2018): «Las campañas en Mesia durante la primera guerra dácica de Trajano (101-102 d. C.): la última tentativa expansionista del estado dacio». Gladius, XXXVIII: 67-87. https://doi.org/10.3989/gladius. 2018.05

\footnotetext{
* Doctor en Historia Antigua por la Universidad de Murcia, davidparmenio@yahoo.es / ORCID iD: https://orcid. org/0000-0003-1142-8662 / Página personal en Academia.edu: https://murcia.academia.edu/DavidSoriaMolina
} 


\section{INTRODUCCIÓN: LA PRIMERA GUERRA DÁCICA DE TRAJANO}

En la primavera del año $101 \mathrm{~d}$. C. el emperador Trajano dio comienzo a la primera de sus campañas contra el Estado dacio, destinada a neutralizar de forma permanente la amenaza que esta entidad, y la entente conformada a su alrededor, suponían para los intereses geopolíticos y estratégicos del Imperio romano e, incluso, para su mera presencia estable en la región. Durante los conflictos sostenidos en 69-70 y 85-89 d. C., el reino dacio y sus aliados habían demostrado tener el potencial necesario para tratar de desplazar al poder romano de la Europa danubiana. Aunque contribuyó a debilitar seriamente a los aliados de Dacia en el entorno de Panonia (88-93 d. C.), la principal aportación al respecto de las campañas de Domiciano en la región fue conseguir evitar la pérdida de territorio romano ${ }^{1}$.

Cuando Trajano accedió a la púrpura la cuestión seguía evidentemente abierta. Al dar comienzo el nuevo siglo, a ojos de los estadistas romanos resultaba evidente que la única solución permanente posible al «problema dacio» pasaba por la desarticulación violenta de la entente dácica y, sobre todo, por la conquista y destrucción del Estado dacio, reafirmando y consolidando la hegemonía romana sobre la región y sus inmediaciones en el proceso ${ }^{2}$. La campaña proyectada para conseguir este objetivo comenzó con una invasión romana dirigida directamente al centro neurálgico del Estado dacio, los montes Orăştie, en la cordillera de los Cárpatos, espacio donde se ubicaban la capital, Sarmizegetusa Regia, así como los principales centros urbanos del reino y las ciudadelas destinadas a protegerlos frente a los intrusos.

Tras imponerse a las fuerzas dácicas en la batalla de Tapae, el ejército romano inició una serie de operaciones destinadas a consolidar el control de los accesos occidentales a la capital dacia y el complejo que la defendía, el cual, dado lo avanzado de la estación, estaba previsto que fuera objeto de un ataque directo durante la campaña del año siguiente ${ }^{3}$. Sin embargo, Trajano no tuvo ocasión de continuar ninguna clase de operación ofensiva a gran escala en los montes Orăştie: a mediados o finales del verano de ese mismo año un poderoso ejército combinado dacio, roxolano y bastarno, secundado por las fuerzas navales y el apoyo técnico proporcionados por Tyras y $\mathrm{Olbia}^{4}$, cayó sobre Mesia Inferior, obligando al emperador a marchar apresuradamente Danubio abajo para atender la defensa de la provincia frente a una auténtica

1 Suetonio, Domit., VI; Casio Dión, LXVII. 6. 1-6; Eutropio, VII. 23. 4; Orosio, Hist. Ad. Paganos, VII. 10. 3-4; Jordanes, Get., XIII. 76-78; Wilkes, 1983: 268-269; Bennett, 1997: 88; Southern, 1997: 92-100; Stefan, 2005: 399-406; Ardevan y Zerbini, 2007: 19; Oltean, 2015: 34-36; Zerbini, 2015: 29-35; Soria Molina, 2016: 189-210; Soria Molina, 2017: 102-109.

2 Daicoviciu, 1984: 151-161; Lepper y Frere, 1988: 278 y 282; Mangas, 2003: 154-156; Stefan, 2005: 532-539; Oltean, 2015: 70-72; Zerbini, 2015: 39-40; Soria Molina, 2016: 211-218 y 221-225.

3 Ardevan y Zerbini (2007: 25) y, posteriormente, Zerbini en solitario (2015: 47) han defendido la hipótesis de que, tras la victoria en Tapae (localizada según ambos autores en las Puertas de Hierro de Transilvania), Trajano procedió a iniciar los asedios de las fortalezas que defendían Sarmizegetusa Regia, haciéndose con el control de Costesti en ese momento. Teniendo en cuenta, no obstante, lo avanzado de la campaña, Glodariu (2000: 109), Opreanu (2000: 391 y 2006: 116) y Stefan (2005: 557-559), consideran que el ejército romano no pudo iniciar ningún asedio en el entorno de la capital Dacia en 101 d. C., y que, por lo tanto, optó por consolidar las posiciones adquiridas y preparar adecuadamente la campaña del año siguiente. Además, las fortalezas dácicas que defendían los accesos a Sarmizegetusa Regia desde las Puertas de Hierro eran Piatra Roşie, Banita y la barrera de Cioclovina-Ponorici, por lo que es imposible que, tras la batalla de Tapae, el ejército de Trajano emprendiera el asedio de Costesti sin haber controlado antes el valle del Mures (para más detalles sobre estas plazas y su posición véase Soria Molina, 2016: 501-514). A ello podemos añadir el hecho de que la Columna Trajana no muestra ningún asedio a una fortaleza dácica de la entidad de Costesti entre las escenas que narran los hechos tras la batalla de Tapae y antes del inicio de la invasión de Mesia Inferior por parte de la entente dácica en el verano-otoño del 101 d. C. (escenas XXVI-XXIX). Para un análisis detallado y actualizado de las operaciones en suelo dacio durante el año 101 d. C. véase: Stefan, 2005: 545-559; Zerbini, 2015: 45-47; Soria Molina, 2016: 227-234.

4 En torno a la presencia de las ciudades griegas de Tyras y Olbia en la entente dácica, las causas y naturaleza de este alineamiento y sus consecuencias véase principalmente: Soria Molina, 2016: 66-67 y 83-87. 
invasión a gran escala que ponía en riesgo no solo la campaña, sino el resultado último de la guerra.

\section{LA INVASIÓN DÁCICA DE MESIA INFERIOR}

Con la inmensa mayoría sus fuerzas desplegadas a las puertas de Buridava bajo las órdenes de su legado, M. Laberio Máximo ${ }^{5}$ y con casi todo el ejército de Mesia Superior concentrado al norte del Danubio, en el interior de Dacia, durante el verano del año 101 d. C. ${ }^{6}$ Mesia Inferior se encontraba en una situación de extrema vulnerabilidad frente a un ataque organizado a gran escala ${ }^{7}$. Probablemente tan sólo las naves de la classis Flauia Moesica ${ }^{8}$, la classis Pontica y las unidades de la classis Rauennatis desplegadas en la zona ${ }^{9}$, así como los destacamentos

5 Opreanu, 2000: 390-391; Stefan, 2005: 550; Opreanu, 2006: 116; Oltean, 2015: 75 y 94-95; Soria Molina, 2016 : 232-233.

6 Buena parte de la historiografía ha defendido tradicionalmente que el ejército de la entente dácica se sirvió de una helada invernal del Danubio para cruzar el río y perpetrar así el ataque sobre Mesia Inferior (Daicoviciu, 1984: 133-134 y 171-172; Blázquez Martínez, 2005: 31-32; Stefan, 2005: 559-568; Opreanu, 2006: 116; Depeyrot, 2008: 52-54; Wheeler, 2010: 1224; Oltean, 2015: 95-117). Esta hipótesis, sin embargo, choca directamente con el hecho de que, según la Columna Trajana (escenas XXXIII-XXXV), Trajano empleó las aguas del Danubio para hacer descender a su ejército en naves hasta Mesia Inferior con la máxima rapidez: esta maniobra habría resultado imposible en caso de encontrarse el Danubio congelado o plagado de témpanos fruto de un deshielo temprano o de una helada parcial (Daicoviciu, 1984: 171-172; Lepper y Frere, 1988: 78-90; Zerbini, 2015: 49-50). En múltiples sentidos, un río helado o parcialmente helado constituía antes una barrera que una ventaja para el movimiento de un gran ejército (Suetonio, Domit., VI; Austin y Rankov, 1995: 173178). A ello cabe sumar la premisa básica de que una campaña en lo más crudo del invierno en Europa central y del Este resultaba inviable para los ejércitos de la Antigüedad, cuya actividad militar a mediana y gran escala cesaba por completo con la llegada del frío hasta la primavera (tal es el caso del ejército romano, como sabemos, por ejemplo, a través de César, Bell. Gall., I. 54; II. 1 y 35; III. 3, 6 y 29; IV. 38; V. 2, 24-31, 37, 39, 41-42, 46-47, 53; VI. 3 у 44; VII. 10 y 90; VIII. 1-2, $4,6,24,46-48,50,52,54)$ : un ejército del tamaño necesario para tomar al asalto plazas fuertes bien fortificadas y ocupar buena parte de una provincia romana (Plinio el Joven, Epist., X. 74. 1; Columna Trajana, escena XXXII) tendría muy pocas posibilidades para abastecerse e incluso para desplazarse por territorio hostil en pleno invierno; la numerosa población no combatiente que acompañaba a los ejércitos roxolanos y bastarnos (escena XXXVIII de la Columna Trajana; metopas IX, XXXV y XL-XLIII del Tropaeum Traiani; Richmond, 1982: 47-50; Coulston, 1988: 359-361; Lepper y Frere, 1988: 298299; Alexandrescu-Vianu, 2006: 222), destinada a asentarse en la Mesia Inferior ocupada, habría perecido en su mayor parte en las duras condiciones del invierno, tanto por el frío como por las dificultades para obtener alimentos. Del mismo modo, la llegada del deshielo, al aproximarse la primavera, o un deshielo temporal en invierno, dejaría completamente aislado y atrapado al ejército invasor, situación extraordinariamente peligrosa. Todos estos factores hacen imposible que los líderes de la entente dácica optaran por desarrollar una campaña a gran escala en Mesia Inferior durante los meses invernales tan sólo para aprovechar una presunta (y nunca segura) helada del Danubio para cruzar a suelo romano. Del mismo modo, resulta totalmente inverosímil que dacios y aliados optaran por cruzar a nado el Danubio, tal y como sostiene Henderson (1968: 261), no sólo porque constituía y constituye una proeza física al alcance de muy pocos, sino por múltiples razones logísticas, técnicas y estratégicas (¡y lógicas!) que lo habrían impedido. Siguiendo estas razones, defendemos que Decébalo y sus aliados optaron por iniciar la invasión de Mesia Inferior a mediados o finales del verano del $101 \mathrm{~d}$. C., extendiéndose las operaciones en la provincia durante los meses de otoño de ese mismo año, siendo realizado el cruce mediante el empleo de naves y quizás puentes de pontones, asegurado además mediante un necesario apoyo de naves de combate capaces de vencer la oposición planteada por las classes romanas y de defender las líneas de suministro y retirada frente a las mismas, situación que, como veremos, dio lugar a múltiples enfrentamientos navales y anfibios durante los acontecimientos que nos ocupan. Para un análisis detallado sobre esta cuestión véase: Soria Molina, 2016: 52-59, 103-110, 136-138, 151-162 y 183-185.

7 Escenas XXXI-XXXII de la Columna Trajana; Plinio el Joven, Epist., X. 74. 1; Daicoviciu, 1984: 171-172; Stefan, 2005: 559-568; Oltean, 2015: 103; Zerbini, 2015: 49.

8 Si bien una parte importante de sus efectivos estaría ocupada también apoyando la expedición de M. Laberio Máximo, así como protegiendo los puntos de cruce del cuerpo principal del ejército romano hacia el interior de Dacia, ubicados en Drobeta, Dierna y Lederata (Reddé, 1986: 356-363; Bounegru y Zahariade, 1996: 98-99; Soria Molina, 2016: 234-235).

9 Sobre la presencia de las classes Pontica y Rauennatis en Mesia Inferior en 101-106 d. C. véase principalmente: CIL III, 14215, 5; Vegecio, IV. 31. 6; Starr, 1960: 125-129; Reddé, 1986: 253, 256-265 y 379; Bounegru y Zahariade, 1996: 12, 19 y 96; Sarnowski, 2006: 256-260; D’Amato, 2009: 8; Pitassi, 2010: 260; Soria Molina, 2016: 514. 
terrestres dejados atrás, se interponían entre las fuerzas de la entente dácica concentradas en el entorno de la Dacia oriental y la provincia de Mesia Inferior.

La invasión de la misma en 101 d. C. debió de ser planeada y concertada por Decébalo con los líderes aliados con antelación suficiente como para poder desarrollarse con fulminante eficacia después del revés sufrido por las fuerzas dácicas en Tapae. Así, el contingente dacio enviado al Este para estas operaciones debía de constituir un ejército independiente del contingente que había resultado vapuleado por la expedición de Trajano en el valle del Mures, desplazado a la región desde la primavera de ese mismo año a la espera de órdenes ${ }^{10}$. En este sentido, Decébalo pudo movilizar alrededor de 20.000 o 25.000 efectivos de sus propias fuerzas para esta campaña ${ }^{11}$, delegando el mando de los mismos en un subalterno ${ }^{12}$. Respecto de las fuerzas aliadas de Dacia, los roxolanos, a las órdenes de Susago ${ }^{13}$, pudieron concentrar hasta 25.000 o 30.000 efectivos, de los cuales en torno a 15.000 serían de caballería ${ }^{14}$. Los bastarnos $^{15}$, por su parte, quizás estuvieron en condiciones de movilizar hasta 35.000 efectivos. En

10 En caso contrario, reorganizar al ejército dacio, movilizar refuerzos y desplazarlos hasta el escenario del combate en la otra punta del Bajo Danubio habría llevado meses. El ejército dacio que protagonizó esta campaña debía de encontrarse ya acantonado en las proximidades del escenario de la misma, junto a los contingentes aliados implicados, para poder iniciar las operaciones en verano, hecho que demuestra que este ataque estaba previsto ya antes del estallido de la guerra. Del mismo modo, estos factores demuestran que este ataque constituía una ofensiva de conquista (sobre la premeditación e intencionalidad expansionista de la invasión de Mesia Inferior en 101 d. C.: Escenas XXXI-XLIII de la Columna Trajana; Metopas IX, XXXV y XL-XLIII del Tropaeum Traiani; Plinio el Joven, Panegyricus, 11. 5; Amiano Marcelino, XXXI. 5. 16; Jordanes, Get., XVIII. 101; Henderson, 1968: 261; Richmond, 1982: 47-50; Wilkes, 1983: 261-263 y 271; Coulston, 1988: 359-361; Lepper y Frere, 1988: 298-299; Mangas, 2003: 156; Stefan, 2005: 559-568; Alexandrescu-Vianu, 2006: 222; Ardevan y Zerbini, 2007: 25; Oltean, 2015: 95-103; Zerbini, 2015: 49-50) y no una mera reacción a la derrota de Tapae con intención de aliviar la presión sobre los montes Orăştie (sobre la invasión de Mesia Inferior en 101 d. C. como una maniobra diversoria: Daicoviciu, 1984: 171-172; Opreanu, 2000: 391; Opreanu, 2006: 116).

11 El potencial humano máximo movilizable por el Estado dacio en $101 \mathrm{~d}$. C. rondaba los 200.000 efectivos (Estrabón, VII. 3. 12; Strobel, 1984: 58-59; Bennett, 1997: 88; Stefan, 2005: 508; Soria Molina, 2016: 37-39). Si en torno a 80.000 de estos efectivos fueron concentrados en los montes Orăştie y la cercana Buridava para asegurar las defensas del reino frente a la invasión romana, es posible que Decébalo pudiera concentrar en el extremo oriental de sus dominios hasta 25.000 efectivos sin arriesgar sus reservas de recursos humanos ni sobrecargar al Estado con una movilización masiva insostenible para su economía. Del mismo modo, este contingente debía de ser lo suficientemente amplio como para poder sitiar con éxito fortificaciones romanas, ocupar el territorio y librar batallas campales a gran escala contra las fuerzas lideradas por el emperador (escenas XXXII, XXXVII-XXXVIII y XL de la Columna Trajana; metopas del Tropaeum Traiani; Plinio el Joven, Panegyricus, 11. 5; Plinio el Joven, Epist., X. 74. 1; Amiano Marcelino, XXXI. 5. 16).

12 La presencia de Decébalo era necesaria en Sarmizegetusa Regia para dirigir la defensa del centro neurálgico del reino dacio tras la derrota sufrida en Tapae. Del mismo modo, la figura del soberano dacio no aparece en las escenas de la Columna Trajana que cubren los acontecimientos de la campaña de Mesia en 101 d. C. (escenas XXXI-XLV). En este sentido, Decébalo debió de confiar el mando sobre las fuerzas dácicas de esta campaña a uno o más miembros clave de la aristocracia dácica, probablemente uno de sus propios hermanos: Vezinas, su sumo sacerdote y probable sucesor (Casio Dión, LXVII. 10. 2; Daicoviciu y Trynkowski, 1970: 164-166; Daicoviciu, 1984: 144) o Diegis (Marcial, Epigramas, V. 3; Casio Dión, LXVII. 7. 2-3).

13 Plinio, Epist., X. 74. 1; Daicoviciu, 1984: 174; Opreanu, 2006: 115; Carbó García, 2007: 293 y 301.

14 Según Tácito, (Hist., I. 79. 1) los sármatas roxolanos fueron capaces de reunir una fuerza de 9.000 jinetes en Mesia en el año 70 d. C., por lo que es probable que esta misma tribu sármata desplegara una cifra superior de caballería en el contexto de una invasión a gran escala en $101 \mathrm{~d}$. C. Junto a la caballería se desplegarían contingentes de infantería no menos numerosos (Metopa XVII del Tropaeum Traiani; Amiano Marcelino, XVII. 13. 9; Brzezinski y Mielckzarek, 2002: 19-2; Lebedynsky, 2010: 30), necesarios para apoyar a la caballería en todas sus acciones, mantener posiciones fortificadas, participar en asedios, etc.

15 Daicoviciu (1984: 171 y 177) y Oltean (2015: 95-97) sostienen que fue la de los buros la tribu germánica que protagonizó la invasión de Mesia Inferior en 101 d. C. junto a dacios y sármatas roxolanos, si bien no descartan la posibilidad de que pudiera tratarse también de los bastarnos. Por su parte, Ardevan y Zerbini (2007: 25) y posteriormente también Zerbini en solitario (2015: 49) consideran sin reservas que fueron los buros el único pueblo germánico que tomó parte en esta campaña. Con la notable excepción de Oltean (2015: 96), ninguno de estos autores tiene en cuenta el testimonio de Tácito (Germ., XLIII. 1-2) en torno a la posición geográfica de los buros al este del macizo bohemio, lo que hace particularmente difícil la participación masiva de esta tribu en esta campaña, y aún más la posibilidad de que iniciaran una migración hacia 
cualquier caso, ambos pueblos, dada su intención de desplazar parte de su población a Mesia Inferior ${ }^{16}$, constituyeron el contingente principal de la entente dácica en la zona, estructurado en torno al núcleo constituido por la fuerza expedicionaria dácica ${ }^{17}$. Las ciudades de Tyras y Olbia, por su parte, apenas habrían podido aportar sendos destacamentos de naves, un pequeño contingente de caballería e infantería combinada, ingenieros y otro personal técnico especializado ${ }^{18}$. Por su parte, las fuerzas que M. Laberio Máximo dejó atrás en su provincia no sumarían más de 5.000 efectivos totales, teniendo en cuenta que precisaba a la gran mayoría de las mismas para controlar la vía hacia los Cárpatos sobre el río Olt y contener a los dacios en torno a Buridava ${ }^{19}$ : así en el verano de 101 d. C. las fuerzas de Mesia Inferior no estaban en condiciones ni de intentar frenar el avance de un enemigo que les multiplicaba varias veces en número; su única oportunidad radicaba en que las classes Flauia Moesica y Rauennatis (quizás acompañadas por destacamentos de la armada del Bósforo) fueran capaces, al menos, de impedir y dificultar el cruce del Danubio a los invasores el tiempo suficiente como para recibir ayuda en cantidades significativas.

El ejército y la armada dácicas debieron partir desde Piroboridava ${ }^{20}$ y Tiason $^{21}$, descendiendo respectivamente sobre las aguas del Siret y del Ialomiţa en dirección al último tramo del curso bajo del Danubio. Los sármatas roxolanos y una parte de sus aliados bastarnos debieron de emplear tres rutas principales: la primera y más importante, partiendo del interior del territorio de ambos pueblos, descendía por el río Prut hasta el Danubio; la segunda salía directamente de la ciudad de Tyras por mar, recorriendo la costa hasta internarse en la desembocadura del Danubio; ambas rutas de invasión enlazaban, llegados a este punto, con la tercera, protagonizada principalmente por los bastarnos peucinos ${ }^{22}$, quienes partiendo de la isla de $P e u c e^{23}$ podían desplazarse por los brazos y canales del delta hasta alcanzar las orillas de Mesia Inferior, o bien remontar el curso del río para cruzarlo un poco más arriba ${ }^{24}$ (Fig. 2).

La columna dácica que descendiera por el río Siret debió de trabar contacto con las classes romanas ya antes de acceder a las aguas del Danubio, dada la presencia de una statio de la

Mesia Inferior (Escenas XXXI-XLIII de la Columna Trajana; Metopas IX, XXXV y XL-XLIII del Tropaeum Traiani) en el contexto de la misma. En este sentido, la mayor parte de la historiografía especializada considera que fueron los bastarnos, y no los buros, quienes tomaron parte activa en la invasión de Mesia Inferior durante la primera guerra dácica de Trajano (Metopas VI, IX, XVII-XXIII, XXVI-XXVII, XXXIV-XXXVII y XL-XLIII del Tropaeum Traiani; Richmond, 1982: 52; Daicoviciu, 1984: 170-173; Coulston, 1988: 323; Lepper y Frere, 1988: 37 y 298-300; Bennett, 1997: 89; Batty, 2007: 354-355; Wheeler, 2011: 193; Soria Molina, 2016: 64-66 y 114-117).

16 Soria Molina, 2018: 89-90.

17 La organización y solidez de su infantería (Soria Molina, 2016: 39-52), así como el material de asedio (Rossi, 1971: 125; Stefan, 2005: 516-522) que estaba a su disposición, hacían del contingente dacio el eje del ejército invasor.

18 El reducido tamaño de las fuerzas armadas de ambas ciudades imposibilitaba a estas para aportar contingentes significativos a nivel numérico (Dión de Prusa, Or., XXXVI. 7 y 15-17; Mielczarek, 1999: 12, 37-38). En este sentido, la principal aportación de las mismas radicaría en medios y asesoramiento técnico, así como la disponibilidad de dos puertos estratégicamente situados en la costa noroccidental del Mar Negro. Véase al respecto Soria Molina, 2016: 98-110.

19 Sobre las fuerzas de la provincia de Mesia Inferior desplegadas al norte del Danubio, en el entorno de Buridava, a las órdenes de M. Laberio Máximo: AE 1969/70, 552-554; Soria Molina, 2016: 401-402. Sobre la campaña del ejército romano en Buridava en 101 d. C. véase: Opreanu, 2000: 390-391; Stefan, 2005: 550; Opreanu, 2006: 116; Oltean, 2015 : 75 y 94-95; Soria Molina, 2016: 232-233.

20 Actual Poiana, Rumanía, condado de Galaţi (Crişan, 1978: 161).

21 Actual localidad de Tinosul, Rumanía, condado de Prahova (Claudio Ptolomeo, Geografía, III. 8. 9; Crişan, 1978 : 166-167).

22 Los peucinos, miembros de la confederación de tribus germánicas constituida por los bastarnos, ocuparon la isla de Peuce (de la cual recibieron el nombre) al menos hasta época de Trajano: Estrabón, VII. 3. 15 y 17; Ovidio, Trist., II. 189-204; Plinio el Viejo, Nat. Hist., IV. 81; Tácito, Germ., XLVI. 1; Claudio Ptolomeo; Geografía, III. 5. 7-10; Jordanes; Get., XII. 74.

${ }_{23}$ Estrabón, VII. 3. 15-17; Tácito, Germ., XLVI. 1; Batty, 2007: 237-239, 245 y 353-355.

24 Soria Molina, 2016: 58-59, 108-110 y 138. 
classis Flauia Moesica en Barboşi ${ }^{25}$. La división que partiera de Tiason, siguiendo el Ialomiţa, haría su aparición en el Danubio río arriba de los primeros combates habidos en el entorno de Barboşi, quizás descendiendo luego el río hasta reunirse con las restantes fuerzas invasoras aguas abajo, atrapando en una maniobra envolvente a las fuerzas navales romanas allí desplegadas. La embestida de la columna bastarno-roxolana procedente del río Prut seguramente tuvo el mismo efecto: tras librar varios combates en la zona, las naves romanas se verían forzadas a emprender la retirada hacia sus bases en la desembocadura del Danubio. El ataque por parte de los bastarnos peucinos, así como la entrada por uno o varios de los canales del delta de la flota combinada greco-roxolana y los destacamentos transportados por la misma, puso ante los comandantes de la flota romana tres opciones: intentar forzar la salida a mar abierto, explotando el hecho de que la prioridad de las fuerzas de la entente dácica radicaría en garantizar el cruce y las líneas de suministros de sus fuerzas; tratar de replegarse, con los mismos argumentos, Danubio arriba hasta Mesia Superior para reagruparse con las fuerzas aliadas, terrestres y navales allí desplegadas; abandonar las naves atrapadas en la maniobra de pinzas enemiga y evacuar las posiciones por tierra. En general, dado que implicaba navegar a favor de la corriente ${ }^{26}$, presentaba múltiples vías de escape, permitía acceder a varios puertos seguros y enlazar con refuerzos procedentes de Anatolia, el mar Egeo y, sobre todo, el Bósforo, los comandantes romanos al mando de los destacamentos atrapados de las classes Flauia Moesica, Rauennatis y Pontica seguramente optaron por salir a mar abierto en espera de poder organizar un contraataque en circunstancias más ventajosas ${ }^{27}$ : lo contrario habría implicado enormes e innecesarias pérdidas en efectivos y naves.

Tras vencer la oposición inicial de la armada romana, las fuerzas navales de la entente dácica concentraron sus esfuerzos en asegurar los puntos de cruce del Danubio, situados en distintos lugares entre los fuertes romanos de Aegyssus y Barboşi ${ }^{28}$. Durante el proceso, la statio de la classis Flauia Moesica en Aliobrix ${ }^{29}$ y las posiciones romanas de Ismail debieron de ser conquistadas por el ejército bastarno-roxolano antes de iniciarse el cruce a Mesia Inferior.

Una vez desplegados en suelo de Mesia Inferior, los ejércitos de dacios, roxolanos y bastarnos procedieron a coordinar sus esfuerzos para la conquista de las plazas fuertes romanas de la región. Es probable que, ante la imposibilidad de resistir la embestida de cuerpos de ejército no inferiores a los 10.000 efectivos, las fuerzas de guarnición romanas optaran por la evacuación de la Dobrudja en dirección al Suroeste. En cualquier caso, las oportunidades de una pequeña guarnición de resistir con éxito un asalto por parte de fuerzas muy superiores, dotadas de artillería y maquinaria de asedio avanzada, respaldadas además por una armada operativa,

25 Situada en Rumanía, en el condado de Brăila. Sobre esta plaza véase: Bounegru y Zahariade, 1996: 11; Wilkes, 2005: 217.

26 Circunstancia que comportaba una importante ventaja táctica en un combate naval, otorgando a la armada situada de este modo la iniciativa para forzar o no el combate, así como la posibilidad de explotar una superior maniobrabilidad.

27 Teniendo en cuenta que la mayor parte de las tripulaciones de la armada de la entente dácica estaban compuestas por fuerzas terrestres embarcadas (Soria Molina, 2016: 56-57), una vez producido el cruce el número de naves de guerra enemigas operativas se reduciría sensiblemente. Al mismo tiempo, las escuadras dácicas y aliadas se verían obligadas a dispersarse por las aguas del Danubio para atender operaciones de apoyo a las fuerzas terrestres, extender el alcance de las líneas de comunicación y suministros, defender estas últimas y mantener abiertos los puntos de cruce seleccionados. En estas circunstancias, las classes romanas, una vez reagrupadas y reorganizadas, con el correspondiente apoyo de fuerzas terrestres, podrían iniciar un contraataque sobre las líneas de la armada de la entente dácica, explotando las ventajas de una probable superioridad numérica local.

28 La columna dácica que descendiera por el Ialomița, no obstante, tenía también la posibilidad de ejecutar un cruce autónomo frente al fuerte romano de Carsium: la aparición de una división del ejército dacio en las proximidades de esta plaza habría situado a la primera en la retaguardia de las fuerzas romanas que defendían la actual Dobrudja, cortando además su vía de retirada más segura.

29 Actual Orlovka, Ucrania, óblast de Odesa (Bounegru y Zahariade, 1996: 11; Wilkes, 2005: 217). 
resultaban muy reducidas ${ }^{30}$. Probablemente sólo las fortalezas de Nouiodunum $^{31}$ y Troesmis $^{32}$ pudieron ofrecer una resistencia significativa a los invasores en el extremo oriental de Mesia Inferior. En cuestión de pocos días tras el desembarco, el ejército de la entente dácica estaría en condiciones de rebasar fuertes romanos como Capidava y de poner cerco a las ciudades costeras de Histria $^{33}$, Tomis $^{34}$ y poco después Callatis $^{35}$, la primera y la última de las cuales de las cuales capitularon o terminaron cayendo en manos de los invasores tras sendos asedios ${ }^{36}$. Las columnas del ejército roxolano, dotadas de una superior movilidad, debieron de ser las primeras en rebasar la futura localidad de Tropaeum Traiani, dirigiéndose hacia el Oeste en dirección a las llanuras del interior, seguidas por los contingentes bastarnos con la intención de barrer cualquier clase de oposición e iniciar la ocupación efectiva de la zona ${ }^{37}$. Su avance debió de servir para aislar las posiciones romanas y las ciudades más cercanas, forzando su capitulación, sitiándolas hasta la llegada del material de asedio necesario para un asalto directo, o conquistándolas directamente sin apoyo técnico en caso de resultar viable. La presencia de las naves de su armada en el Danubio permitía a los ejércitos de la entente dácica extender fácilmente sus líneas de suministro hacia el Oeste, así como transportar rápidamente piezas de artillería y la pesada maquinaria de asedio, liberando a las fuerzas terrestres de una gran cantidad de impedimenta, lo que incrementaría notablemente su movilidad ${ }^{38}$. En septiembre la fortaleza romana de Durostorum ${ }^{39}$ ya habría caído en manos de los invasores, así como todas las plazas situadas en la trayectoria hasta ella. Las fuerzas de la entente dácica no empezaron a encontrar resistencia capaz de contener su avance hasta alcanzar la fortaleza legionaria de Nouae, a la que pusieron sitio (Fig. 3) ${ }^{40}$. El ejército roxolano, en su mayor parte asignado a la vanguardia de la invasión, abandonó el asedio de Nouae y se dirigió unos $50 \mathrm{~km}$ al Sur para

30 Escena XXXII de la Columna Trajana; Daicoviciu, 1984: 172 y 177-178; Opreanu, 2000: 391; Mangas, 2003: 156; Stefan, 2005: 559 y 561; Opreanu, 2006: 116; Ardevan y Zerbini, 2007: 25; Oltean, 2015: 103; Zerbini, 2015: 49-50.

31 Actual Isaccea, en Rumanía, condado de Tulcea (Bounegru y Zahariade, 1996: 11; Wilkes, 2005: 217).

32 Actual Iglița Turcoaia, Rumanía, condado de Tulcea (Bounegru y Zahariade: 11; Wilkes, 2005: 216).

33 Actual Istria, Rumanía, condado de Constanța (TIR L 35: 45; MacKendrick, 1975: 21-25 y 34; Bounegru y Zahariade, 1996: 80-81).

34 Actual Constanţa, Rumanía, condado homónimo (MacKendrick, 1975: 34-38; Bounegru y Zahariade, 1996: 78-79).

35 Actual Managlia, Rumanía, condado de Constanţa (Rodríguez González, 2003: 312-314; MacKendrick, 1975: 3842; Bounegru y Zahariade, 1996: 75-78).

36 Resulta significativo que el ejército romano destinara en 106-107 d. C. sendas uexillationes de la legión XI Claudia a Histria y Callatis (al respecto: TIR L 35: 45; MacKendrick, 1975: 21-25, 34 y 38-42; Bounegru y Zahariade, 1996: 7578 y 80-81; Rodríguez González, 2003: 312-314; Soria Molina, 2016: 372). Su presencia indica que ambas plazas eran tenidas por vulnerables frente a amenazas exteriores a gran escala, bien por la facilidad con que podían ser conquistadas mediante un ataque realizado por un ejército que consiguiera penetrar en la Dobrudja, bien porque, ante semejante circunstancia, sus autoridades fueran propensas a salvaguardar sus respectivas ciudades capitulando sin ofrecer resistencia.

37 La dirección de la ofensiva de los sármatas roxolanos y los bastarnos puede indicar qué espacios pretendían ocupar con la población inmigrante que acompañaba a sus ejércitos. En este sentido, parece que ambos grupos sintieron una especial predilección por el interior de Mesia Inferior, tal y como deja traslucir el punto donde tuvieron lugar las batallas de Nicopolis ad Istrum y Tropaeum Traiani, (Metopas del Tropaeum Traiani; Amiano Marcelino, XXXI. 5. 16; Jordanes, Get., XVIII. 101), dejando así los espacios costeros y sus ciudades en manos de la ocupación dácica (patrón que encajaría con las prioridades expansionistas geto-dácicas en la región: Crişan, 1978: 124-125 y 131; Matyszak, 2005: 168; Stefan, 2005: 380-382; Vădan, 2007-2008: 73-79; Soria Molina, 2014: 141-145; Soria Molina, 2016: 23-26 y 32-33).

38 Si bien hacía que estos ejércitos dependieran igualmente en exceso de las fuerzas navales para mantener sus operaciones, espacialmente a nivel logístico. Esta circunstancia constituía una vulnerabilidad, dado que, en caso de que la flota de la entente dácica fuera forzada a retroceder, los ejércitos en tierra se verían privados de un apoyo esencial y obligados a retirarse hacia posiciones bajo mejor cobertura logística.

39 Actual Silistra, Bulgaria, provincia de Silistra (Bounegru y Zahariade, 1996: 14-15; Wilkes, 2005: 215).

40 Nouae experimentó una intensa actividad constructiva datada a finales del año $101 \mathrm{~d}$. C. que ha sido puesta en relación con la reparación de los daños producidos por un asedio de la plaza a manos de los dacios y sus aliados (Stefan, 2005: 561). Sobre Nouae, actual Svishtov, Bulgaria, provincia de Veliko-Tŭrnovo, véase: Bounegru y Zahariade, 1996: 10-11; Wilkes, 2005: 213. 
hacerse con el control de la futura localidad de Nicopolis ad Istrum ${ }^{41}$, dejando atrás a los contingentes dacios y bastarnos que les acompañaban.

Llegado a este punto, el ejército de la entente dácica había estirado al máximo sus líneas de suministro ${ }^{42}$ en Mesia Inferior, dejando tras de sí guarniciones a cargo de mantener las plazas de mayor valor estratégico. Es posible que las operaciones de asedio a Callatis y especialmente Tomis continuaran todavía ${ }^{43}$, obligando a los invasores a dispersar aún más sus efectivos. La situación de su armada era incluso más delicada, falta de efectivos para mantener operativo un número de naves equiparable al desplegado al inicio de la invasión y obligada a dispersar sus fuerzas para el mantenimiento de las líneas de suministro y transporte de tropas. Las fuerzas invasoras quedaron divididas en dos cuerpos principales: un ejército de vanguardia, compuesto predominantemente por sármatas roxolanos y dacios agrupados en torno a Nouae y Nicopolis ad Istrum, iniciando preparativos para defender la región ocupada e invernar en ella; otro ejército, compuesto por un núcleo de fuerzas dácicas y una mayoría de contingentes bastarnos, dividido entre Durostorum y los asedios de Tomis y Callatis ${ }^{44}$. Más allá, una multiplicidad de guarniciones mantenían las plazas conquistadas más significativas, así como las vías de comunicaciones con Dacia.

\section{LA REACCIÓN ROMANA}

Cuando las noticias de la invasión de Mesia Inferior llegaron hasta Trajano, el ejército romano se encontraba todavía enfrascado en concluir la conquista y puesta a punto de los accesos occidentales a los montes Orăştie. En este sentido, el emperador tenía dos opciones.

41 Sobre la presencia de los roxolanos en Nicopolis ad Istrum en el verano-otoño de 101 d. C.: Escena XXXVII de la Columna Trajana; Amiano Marcelino, XXXI. 5. 16; Jordanes, Get., XVIII. 101; Stefan, 2005: 559-568; Depeyrot, 2008: 62-63; Oltean, 2015: 103-104; Zerbini, 2015: 51; Soria Molina, 2016: 239-240.

42 Sobre el alcance máximo de la invasión dácica, roxolana y bastarna en Mesia Inferior en 101 d. C. véase: Henderson, 1968: 261; Daicoviciu, 1984: 170-178; Opreanu, 2000: 391; Mangas, 2003: 156; Stefan, 2005: 559-568; Opreanu, 2006: 116; Ardevan y Zerbini, 2007: 25-26; Depeyrot, 2008: 62-63; Oltean, 2015: 103-104; Zerbini, 2015: 50-51; Soria Molina, 2016: 240 .

43 Las fuerza navales romanas que se hubieran retirado a mar abierto, podrían haber ayudado en la defensa de estas plazas (no obstante, Histria quizás fue abandonada ante la prontitud de su asedio), impidiendo un bloqueo naval de las mismas, aportando contingentes de soldados entrenados para asistir a los improvisados defensores y proporcionando los necesarios suministros durante los sitios. Si, como suponemos, Tomis no fue finalmente conquistada por los invasores (no recibió ninguna clase de guarnición al término de las guerras dácicas de Trajano, a diferencia de sus dos vecinas, Histria y Callatis), podría ser debido a que, en buena medida, las flotas romanas concentraron en ella sus esfuerzos con éxito, hecho en el que su configuración geográfica (se asentaba sobre una península: MacKendrick, 1975: 34-38; Bounegru y Zahariade, 1996: 78-79) habría resultado de gran ayuda a los defensores romanos por tierra y mar.

44 El ejército concentrado en torno a Nicopolis ad Istrum no habría estado en condiciones de oponer posteriormente una dura resistencia en el campo de batalla de Tropaeum Traiani frente a un ejército romano de mayor tamaño y mejor pertrechado que continuaba su contraofensiva: una buena parte del ejército de la entente dácica debió de quedar en la mitad oriental de Mesia Inferior, ocupada en satisfacer los objetivos particulares de dacios y bastarnos puestos en esta campaña, permitiéndole luego marchar hacia el Oeste al encuentro de los restos de las fuerzas derrotadas en Nicopolis para reagruparse y presentar batalla al ejército de Trajano en Tropaeum. En este sentido, los relieves de la Columna Trajana (escenas XXXVII-XL) y las metopas del Tropaeum también dan a entender la división del ejército invasor en dos grandes cuerpos con una composición sensiblemente distinta (uno compuesto por sármatas roxolanos, otro por bastarnos, y ambos completados por un núcleo de fuerzas dácicas): en particular la secuencia de escenas de la Columna deja traslucir que los acontecimientos se sucedieron con cierta rapidez, sin que entre las batallas de Nicopolis y Tropaeum transcurriera el tiempo necesario como para que el ejército derrotado junto a la primera localidad pudiera reagruparse en el número necesario como para luchar luego en Tropaeum sin la ayuda de otro gran ejército aliado que se encontrara operativo de antemano en la Dobrudja. Sobre la división del ejército de la entente dácica en dos cuerpos independientes: Amiano Marcelino, XXXI. 5. 16; Jordanes, Get., XVIII. 101; Daicoviciu, 1984: 172-173; Ardevan y Zerbini, 2007: 25-26; Oltean, 2015: 104-110; Zerbini, 2015: 51; Soria Molina, 2016: 238-240. 
La primera y, aparentemente, la más sensata implicaba desplazar a la mayor parte del ejército desplegado en Dacia hacia el Sureste, reagrupar a este con las fuerzas de M. Laberio Máximo y, una vez hecho, afrontar la liberación de Mesia Inferior con las mejores garantías posibles. Sin embargo, esta opción significaba perder todos los avances realizados durante la campaña de los meses anteriores, incluidas las ventajas obtenidas de la costosa victoria en Tapae, lo que frustraría las expectativas puestas en la campaña proyectada para el año siguiente. Al mismo tiempo, desplazar a todo el ejército desde Dacia hacia Mesia Inferior y organizar el contraataque con estas fuerzas implicaba una dilatada y laboriosa maniobra no exenta de riesgos, y en ningún caso garantizaba totalmente la victoria ${ }^{45}$. Además, en el caso de que la totalidad del gran ejército concentrado para la invasión de Dacia resultara derrotado, las consecuencias resultarían catastróficas para los romanos a todos los niveles ${ }^{46}$.

La segunda opción implicaba desplazar tan sólo a una sección del ejército desplegado en Dacia, dejando atrás a la mayor parte de las fuerzas en número suficiente como para continuar las operaciones previstas. La fuerza expedicionaria seleccionada, al mando del emperador, marcharía con la mayor rapidez posible para reunirse con el ejército de M. Laberio Máximo en Mesia Inferior e iniciar inmediatamente el contraataque contra las fuerzas invasoras más cercanas, a fin de no darles tiempo a coordinar sus acciones frente a la respuesta romana, obligándolas a luchar separadas y confundiendo a sus mandos ${ }^{47}$. Aprovechando estas ventajas,

45 Aunque el ejército romano disponía de variados medios para tratar de conocer la posición, dirección y entidad de los ejércitos enemigos desplegados en Mesia Inferior, en ningún caso sus comandantes tendrían una información exacta que les permitiera actuar con una seguridad completa de que sus fuerzas no se verían obligadas a confrontar una situación peligrosamente adversa. En buena medida, a las puertas del otoño de 101 d. C., el emperador probablemente no sabía qué estaba sucediendo más al Este de Nouae, Nicopolis ad Istrum y sus alrededores, cortada toda comunicación con posiciones romanas más orientales y, sobre todo, dadas las dificultades para que los exploratores, procursatores y speculatores del ejército romano pudieran penetrar aún más en Mesia Inferior con el objetivo de localizar a los ejércitos enemigos, averiguar su ruta y sus objetivos más probables, y regresar para informar a sus mandos (sobre la inteligencia táctica en el ejército romano véase principalmente: Austin y Rankov, 1995: 39-86; Mattern, 1999: 66-80). El inicio de la escena XXXVII de la Columna Trajana, de hecho parece representar a sendos exploratores del ejército de Trajano informando al emperador sobre la localización del ejército roxolano antes de la batalla de Nicopolis and Istrum. Además, la batalla de Tapae se había librado en un escenario que impedía a los dacios y sus aliados explotar su superioridad numérica, mientras que en Mesia Inferior la caballería roxolana y otras fuerzas tenían todo el espacio necesario para sacar provecho de su maniobrabilidad y tratar de rebasar a sus oponentes romanos mediante maniobras de flanqueo. Las posibilidades de una derrota desde el punto de vista de Trajano eran importantes. Al mismo tiempo, si reunía un gran ejército para tratar de compensar esta circunstancia, el tiempo necesario para movilizarlo habría permitido al ejército invasor consolidar sus posiciones y, sobre todo, reagruparse, descansar y reunir refuerzos. El desconocimiento y la inseguridad de la situación, por lo tanto, debieron de condicionar fuertemente las decisiones de Trajano y su estado mayor.

46 Para empezar, las pérdidas obligarían a los romanos a replegarse, abandonando todas las posiciones conquistadas en 101 d. C., y a mantenerse a la defensiva mientras tuviera lugar la reunión de refuerzos, dañando seriamente la moral de sus tropas. Otros frentes habrían de ser desguarnecidos con el objetivo de suplir las bajas sufridas y estar en condiciones de contraatacar con la mayor rapidez posible, multiplicando los riesgos de revueltas o amenazas exteriores (Mattern, 1999: 94-99; Kagan, 2006: 355-356; Mattern, 2012). Mesia Inferior no podría ser liberada hasta el año siguiente, dando tiempo a la entente dácica a consolidar la ocupación. El emperador, además, sufriría un fuerte descrédito a causa de esta derrota, hecho que podía desembocar en una seria inestabilidad política en la retaguardia. Entre tanto, la situación dejaba las manos libres a los invasores para progresar o extender sus acciones a provincias vecinas. Movilizar a todo el ejército concentrado para la guerra en tales circunstancias era, por lo tanto, una apuesta muy arriesgada escondida tras una apariencia de sensatez.

47 Recordemos que, al igual que Trajano, los comandantes dacios, roxolanos y bastarnos no tenían una idea exacta de cuál iba a ser la respuesta romana, cuando tendría lugar y qué cantidad de fuerzas serían enviadas contra ellos. Es posible que los líderes invasores confiaran excesivamente en el tamaño de sus fuerzas, cometiendo errores que favorecieran el contraataque romano (tales como tratar de abarcar más espacios de los que realmente podrían defender). En este sentido, una pronta, calculada e inesperada reacción romana podía sembrar la confusión e incluso el pánico entre los dacios y sus aliados, al verse los invasores atacados antes de lo que hubieran previsto, sin saber con seguridad si tan sólo peleaban contra una avanzadilla solitaria o si la mayor parte de las fuerzas romanas se había reagrupado en un tiempo récord y estaba próxima a sus posiciones. Probablemente Trajano trató de explotar al máximo esta baza psicológica a su favor. 
otras fuerzas procedentes de Panonia, así como aquellas que hubieran quedado en reserva en Mesia Superior tendrían tiempo de acudir para continuar la campaña de liberación de Mesia Inferior. Aunque los riesgos de esta audaz maniobra eran también muchos ${ }^{48}$, permitía mantener activo el frente en el interior de Dacia, disponer de una reserva en caso de ser precisas más fuerzas en grandes cantidades y explotaba las ventajas de un veloz ataque relámpago contra un ejército enemigo que necesitaría reorganizarse para hacer frente a un contraofensiva a gran escala. Fundamentalmente, esta estrategia tenía como principal ventaja arrebatar la iniciativa a las fuerzas de la entente dácica e impedir que todos los logros de la campaña en Dacia de los meses anteriores cayeran en saco roto.

Como sabemos, Trajano se decantó por la segunda opción. En respuesta a la necesidad de actuar con la máxima rapidez y contundencia posibles, el emperador reunió una fuerza expedicionaria compuesta por sus fuerzas de élite más móviles: sus equites singulares Augusti, caballería auxiliar selecta y caballería legionaria; infantería de choque formada principalmente por cuerpos auxiliares especializados, pedites singulares, irregulares y aliados germánicos de la guardia personal de Trajano ${ }^{49}$. Esta fuerza partió a las órdenes directas del emperador desde las posiciones romanas en el interior de Dacia, embarcando en el Danubio para poder hacer acto de presencia en el teatro de operaciones a la mayor brevedad posible, seguidas por los efectivos de las classes Flauia Moesica y Pannonica que se encontraran desplegadas en Mesia Superior ${ }^{50}$. En vanguardia se encontraba también el ejército de Mesia Inferior que, a las órdenes de M. Laberio Máximo, había estado bloqueando hasta entonces Buridava y el valle del Olt: la mayor parte de estas tropas (unos 15.000 efectivos) debían de encontrarse reunidas ya en Oescus junto a las naves de la classis Flauia Moesica que las habían acompañado al inicio del conflicto, sumadas a las fuerzas que, en retirada desde la Dobrudja, hubieran ido llegando a la zona ${ }^{51}$. Tras esta punta de lanza Trajano movilizó también las cohortes pretorianas disponibles, uexillationes legionarias y otras unidades pesadas seleccionadas del ejército romano de Dacia. Este contingente habría de reunirse con las fuerzas que hubieran quedado en Mesia Superior durante la campaña para dirigirse allí donde se encontraran el emperador y la vanguardia de la expedición ${ }^{52}$. Finalmente, la fuerza principal de la classis Flauia Pannonica

48 El principal peligro radicaba en que el ejército enemigo lograra reagruparse antes de lo estimado, que estuviera menos disperso de lo calculado, que la reacción enemiga ante el efecto sorpresa no fuera la esperada o una combinación de todos ellos.

49 Propuesta planteada principalmente por Speidel (2004: 3-8) en torno al ejército de Trajano representado en las escenas XXXVI, XXXVIII, XL y XLII de la Columna Trajana. Según el criterio de este autor, resulta improbable que (tal y como han defendido: Richmond, 1982: 20; Coulston, 1988: 296-297; Lepper y Frere, 1988: 84-85 y 88-89; Zerbini, 2015: 81) un monumento como la Columna Trajana represente al emperador rodeado por meras fuerzas auxiliares o irregulares. En este sentido, Speidel defiende que las fuerzas de apariencia irregular representadas en las citadas escenas no son sino parte de la élite y especialistas del ejército romano, así como unidades de origen germánico de la guardia personal del emperador. La naturaleza particular de estas fuerzas (Speidel, 2004: 3-8) nos desvela así los objetivos y la estrategia planteadas por el emperador Trajano para la campaña en Mesia Inferior: una intervención rápida y fulminante que desconcertara y desorganizara a las fuerzas invasoras mediante un contundente ataque realizado con fuerzas especializadas de absoluta confianza, dando tiempo, además, a que unidades más pesadas (pero también más lentas), como las legiones, pudieran movilizarse y unirse a la campaña.

50 Escenas XXXIII-XXXVI de la Columna Trajana; Starr, 1960: 134; Henderson, 1968: 261-262; Lepper y Frere, 1988: 83-84; Bounegru y Zahariade, 1996: 101; Opreanu, 2000: 391; Stefan, 2005: 563-568; Opreanu, 2006: 116; Depeyrot, 2008: 55-60; Pitassi, 2010: 260-261; Pogorzelski, 2012: 52-54; Oltean, 2015: 103; Zerbini, 2015:50.

51 Al saber de la invasión de la provincia bajo su responsabilidad, M. Laberio Máximo debió de descender el Olt con las fuerzas que tenía desplegadas en torno a Buridava (o parte de ellas) para asumir el mando de la defensa de Mesia Inferior hasta la llegada del emperador con un ejército de socorro (escena XXXV de la Columna Trajana; Stefan, 2005: 567, fig. 235; Oltean, 2015: 103).

52 La Columna Trajana muestra una ausencia total de infantería legionaria y pretorianos en las escenas XXXVIXXXVIII, correspondientes a las fases iniciales de la campaña y la batalla de Nicopolis ad Istrum (Depeyrot, 2008: 60-65; Stefan, 2005: 561; Oltean, 2015: 105-108). Este tipo de fuerzas tan solo reaparecen a partir de la escena XXXIX, 
debió de acompañar a un importante destacamento del ejército de Panonia a las órdenes del legado de la provincia, Q. Glitio Atilio Agrícola (quizás unos 10.000 o 15.000 efectivos) ${ }^{53}$, destinados ambos a sumarse al contraataque en cuanto fuera posible ${ }^{54}$.

\section{DESENLACE: LAS BATALLAS DE NICOPOLIS AD ISTRUM Y TROPAEUM TRAIANI}

Reunida la vanguardia del ejército de Trajano con los contingentes desplazados por M. Laberio Máximo en Oescus $^{55}$ la expedición se dirigió de inmediato hacia Nouae (Fig. 3). La classis Flauia Moesica se abrió paso mediante un enérgico y contundente ataque ${ }^{56}$, obligando a retroceder apresuradamente a las sorprendidas fuerzas navales de la entente dácica. Este movimiento dejó al ejército dacio que asediaba Nouae sin su principal línea de suministros, obligándole a levantar el cerco y a retroceder preventivamente hacia el Sureste, con la intención de reunirse con las fuerzas de sus aliados roxolanos ${ }^{57}$. Sin embargo, Trajano se adelantó a estas intenciones pues, conociendo la presencia del ejército roxolano en Nicopolis ad Istrum, se dirigió rápidamente con su ejército hasta esa localidad ${ }^{58}$. El énfasis puesto por el emperador en la maniobrabilidad, la velocidad y la contundencia obtuvo su recompensa, al evitar que los roxolanos pudieran unir sus fuerzas a las de sus aliados a tiempo ${ }^{59}$. De este modo, un fulmi-

recobrando el protagonismo en la escena XL, correspondiente a la batalla de Tropaeum Traiani (Depeyrot, 2008: 68-72; Oltean, 2015: 109). Del mismo modo, las metopas del Tropaeum Traiani (por ejemplo las XII-XIV, XVII-XXII, XXVI, XXXIX, XLI y XLIV) muestran ya legionarios y fuerzas regulares implicadas en los acontecimientos relativos a la batalla librada en el lugar donde fue erigido este monumento, es decir, en una fase más avanzada de la campaña. En este sentido véase Speidel, 2004: 7.

53 Soria Molina, 2016: 403-404.

54 La corona classica de Q. Glitio Atilio Agrícola (CIL V, 6977 = ILS 1021) permite constatar que, como legado de Panonia (Fasti Prouinciales), este comandante romano intervino al mando de la classis Pannonica en el único frente susceptible de albergar un choque a gran escala entre la flota romana y una flota enemiga de entidad suficiente, es decir, durante la campaña de Mesia Inferior en $101 \mathrm{~d}$. C. En este sentido, es igualmente probable que el ejército de Panonia navegara Danubio abajo (Starr, 1960: 134; Bounegru y Zahariade, 1996: 101; Pitassi, 2010: 260-261), a las órdenes de su comandante, para sumarse al contraataque romano liderado por Trajano en Mesia Inferior con la mayor prontitud posible.

55 Depeyrot (2008: 59) y Oltean (2015: 103) han propuesto, en cambio, que el lugar de desembarco de Trajano y sus tropas tras la travesía por el Danubio (escenas XXXIII-XXXIV de la Columna Trajana) tuvo lugar en Nouae. Aunque no podemos descartar tajantemente esta hipótesis, Stefan (2005: 566) considera más probable que Trajano desembarcara con sus fuerzas en Oescus, teoría que estimamos razonable: si tenemos en cuenta que Nouae, situada un poco más al este, presenta señales de haber sido reconstruida como consecuencia de los daños recibidos en un violento asedio atribuible a esta campaña (Stefan, 2005: 561) el ejército al mando del emperador no habría podido desembarcar con seguridad (escena XXXV de la Columna Trajana) en una plaza asediada por el enemigo, ni mucho menos si esta ya había sido ocupada por los dacios. En este sentido, Oescus habría resultado una opción más lógica y segura, permitiendo a las fuerzas romanas organizarse antes de iniciar el ataque sobre las posiciones dacias y roxolanas.

56 El cual pudo ya motivar la concesión de algunas de las primeras coronae classicae de la contienda (CIL VI, 1444 = AE 2000, 135; CIL XII, 3169 = AE 1982, 678; CIL XI, 1833 = IDRE 1, $128=$ AE 1926, 123 = AE 1987, 392; Soria Molina, 2016: 151-157).

57 Teniendo en cuenta que Nouae estaba bajo asedio (Stefan, 2005: 561), debió de ser el primer objetivo del ejército de Trajano, tanto por esta razón como por su cercanía y alto valor estratégico. Es posible que los sitiadores levantaran el cerco y se replegaran al conocer la llegada a la zona de una expedición de socorro (la Columna Trajana no muestra ningún enfrentamiento entre el desembarco de Trajano en Mesia Inferior en la escena XXXV y el inicio de la batalla de Nicopolis ad Istrum en la escena XXXVII), tratando de reagruparse con otras fuerzas aliadas próximas para evaluar la situación y proceder en consecuencia.

58 Escenas XXXVI-XXXVII de la Columna Trajana; Amiano Marcelino, XXXI. 5. 16; Jordanes, Get., XVIII. 101; Depeyrot, 2008: 60-63; Oltean, 2015: 104-105; Zerbini, 2015: 50-51; Soria Molina, 2016: 244.

59 La Columna Trajana muestra claramente dos enfrentamientos separados (Lepper y Frere, 1988: 85; Depeyrot, 2008: 62-65; Pogorzelski, 2012: 54-58; Oltean, 2015: 104-108), si bien consecutivos, pues ninguna escena media entre ambos: uno contra los sármatas roxolanos, librado esencialmente por la caballería romana (escena XXXVII), y otro contra los dacios, protagonizado por las tropas germánicas y la caballería de Trajano (escena XXXVIII). En este sentido, 
nante ataque combinado de la caballería y la infantería romanas infligió una seria derrota a los roxolanos, quienes se vieron forzados a huir con serias pérdidas en dirección al Este por el interior ${ }^{60}$. La noticia de la derrota de sus aliados roxolanos debió de afectar seriamente a la moral de las fuerzas dácicas que marchaban apresuradamente hacia Nicopolis ad Istrum. Es posible que consiguieran reunirse con parte de las fuerzas roxolanas en fuga, con la ayuda de las cuales intentaron revertir la situación y rechazar el vigoroso ataque romano. La batalla volvió a saldarse con la derrota de la entente dácica, siendo desarticulada así la vanguardia de la invasión daco-bastarno-roxolana de Mesia Inferior ${ }^{61}$. Los restos de este ejército emprendieron una apresurada retirada hacia el Este (Fig. 3).

Trajano debió de regresar a orillas del Danubio con el objetivo de recuperar las plazas fuertes pérdidas, mantener el enlace con la classis Flauia Moesica y continuar el avance manteniéndose al alcance de los primeros refuerzos procedentes de Dacia, Mesia Superior y Panonia. La flota romana tuvo un papel esencial en la segunda fase de la contraofensiva romana, apoyando el asalto a aquellas plazas ocupadas que opusieran resistencia, manteniendo la presión sobre la armada de la entente dácica, atacando las líneas de suministro fluviales de las fuerzas invasoras y escoltando a las unidades del ejército en sus desplazamientos por el río hacia el frente ${ }^{62}$. La llegada de las naves de la classis Flauia Pannonica y de las ansiadas uni-

Depeyrot (2008: 62-63) y Oltean (2015: 104-105) han propuesto que el enfrentamiento contra los roxolanos no puede ser atribuido a la batalla de Nicopolis ad Istrum, sino que constituye un episodio inmediatamente anterior a la auténtica batalla que tuvo lugar en torno a esta localidad. Ambos autores ignoran el testimonio conjunto de Amiano Marcelino (XXXI. 5. 16) y Jordanes (Get., XVIII. 101), que atribuye tanto la derrota de los roxolanos como la del ejército dacio a la batalla de Nicopolis ad Istrum, coincidiendo directamente con las escenas de la Columna Trajana. Desde nuestro punto de vista, los testimonios literarios e iconográficos existentes en torno a esta primera fase de la campaña de Trajano en Mesia Inferior permiten considerar que en Nicopolis ad Istrum se libraron dos batallas diferentes, con no más de unos días de diferencia, en el mismo campo de batalla (dado que la Columna Trajana no presenta ningún episodio entre ambas que permita considerar el paso de más tiempo, o el desplazamiento del ejército de Trajano de un lugar a otro entre ambas batallas): el primero contra los roxolanos, quienes se encontraban ya en la zona; el segundo contra un ejército dacio que, como veremos, probablemente acudía para unir sus fuerzas a las de los roxolanos. Esta interpretación es, a nuestro parecer, la única que permite reconciliar la información procedente de las fuentes literarias con aquella proporcionada por la Columna Trajana.

60 Escena XXXVII de la Columna Trajana; Jordanes, Get., XVIII. 101; Stefan, 2005: 560; Opreanu, 2006: 116; Ardevan y Zerbini, 2007: 25-26; Depeyrot, 2008: 62-63; Oltean, 2015: 104-105; Zerbini, 2015: 51; Soria Molina, $2016: 244$.

61 Stefan (2005: 563) considera que la escena XXXVIII de la Columna Trajana corresponde a la batalla librada en Tropaeum Traiani, dado que tanto en el primer monumento como en las metopas IX, XXXV y XL-XLIII del Tropaeum se representa la presencia de carros en el campo de batalla y la lucha entre los mismos. Semejante reconstrucción de los hechos resulta insostenible, dado que la Columna Trajana plantea con claridad que la batalla entre carros representada en sus relieves pertenece al inicio de la campaña de Trajano en Mesia Inferior, sucediendo inmediatamente después de la batalla contra los roxolanos, que inaugura dicha campaña. De hecho, la escena XXXVIII de la Columna Trajana no muestra a ningún legionario o miembro de la infantería pesada romana combatiendo en esta batalla, mientras que en las metopas del Tropaeum Traiani protagonizan casi todas las escenas de combate. Del mismo modo, el Tropaeum no representa a ningún combatiente de apariencia germánica luchando contra los bastarnos, tal y como sí hace la citada escena de la Columna. El propio Stefan (2005: 560) plantea la hipótesis de que la plaza en construcción que aparece en la escena XXXIX de la Columna puede ser la propia Nicopolis ad Istrum, lo que invalidaría de inmediato cualquier posibilidad de que la escena XXXVIII corresponda a la batalla de Tropaeum. La mayor parte de la historiografía reciente, por lo tanto, coincide en considerar que la batalla entre carros de la escena XXXVIII de la Columna Trajana es la de Nicopolis ad Istrum (Depeyrot, 2008: 64-65; Oltean, 2015: 105-108), o que, simplemente, las batallas representadas en el Tropaeum Traiani y en la escena XXXVIII de la Columna Trajana no son, ni mucho menos la misma (Lepper y Frere, 1988: 85). Oltean (2015: 106-107) plantea una interesante y a la vez sencilla solución al dilema: aunque las batallas representadas en la escena XXXVIII de la Columna y en el Tropaeum Traiani no corresponden al mismo encuentro, posiblemente los artistas de ambos monumentos quisieron simplemente enfatizar una extraordinaria presencia de grandes carros de transporte en las líneas de la entente dácica durante la invasión de Mesia Inferior. Sobre la derrota sufrida por los dacios en Nicopolis ad Istrum: escena XXXVIII de la Columna Trajana; Amiano Marcelino, XXXI. 5. 16; Opreanu, 2000: 391; Stefan, 2005: 563; Opreanu, 2006: 116; Ardevan y Zerbini, 2007: 25-26; Depeyrot, 2008: 64-65; Oltean, 2015: 105-108; Zerbini, 2015: 51; Soria Molina, 2016: 244-245.

62 Para un análisis detallado del papel de la armada romana en el conflicto véase Soria Molina, 2016: 151-162. 
dades de refuerzo ${ }^{63}$ dieron un nuevo impulso al contraataque, permitiendo extender el alcance de las operaciones en tierra y en el Danubio: las classes romanas debieron de protagonizar en este momento una ofensiva a gran escala, enfrentándose en varios encuentros de gran envergadura a las escuadras enemigas y derrotándolas ${ }^{64}$. Reunidas todas las fuerzas esperadas, el emperador Trajano continuó el avance hacia la Dobrudja en busca del enemigo (Figs. 3 y 4).

El segundo cuerpo del gran ejército desplegado por la entente dácica en Mesia Inferior debió de abandonar las plazas de Tomis y Callatis para dirigirse hacia el Oeste en cuanto sus mandos tuvieron noticia de la derrota de las divisiones de vanguardia en Nicopolis ad Istrum, reuniéndose con aquellas fuerzas que, en su apresurada retirada desde Occidente, lograron darles alcance. El encuentro decisivo tuvo lugar en el entorno de la futura localidad de Tropaeum Traiani $^{65}$ : la batalla comenzó con una feroz refriega de caballería ${ }^{66}$, seguida por el encuentro entre la infantería pesada de ambos bandos; las líneas daco-bastarnas no resistieron el ataque romano y finalmente cedieron, retrocediendo hasta su campamento ${ }^{67}$; allí, la infantería romana continuó su avance, aniquilando las bolsas de resistencia enemigas ${ }^{68}$; la caballería roxolana y dacia, carente del apoyo de su infantería y presionada de cerca por los jinetes romanos, se replegó hasta emprender la huida. A costa de numerosas pérdidas, el ejército de Trajano se alzó con una victoria que decidió no solo la campaña, sino el curso de la guerra a favor de las armas romanas.

Los restos del ejército dacio debieron de retirarse hacia los puntos por los que había cruzado en verano. Con el objetivo de cortarles esta vía de escape, las classes romanas probablemente emprendieron una vertiginosa ofensiva logrando, quizás, interceptar a varios contingentes en el Danubio ${ }^{69}$, obligar a otros a desplazarse hacia el Este en busca de nuevas vías

63 La escena XXXIX de la Columna Trajana muestra ya a grupos de legionarios construyendo o reparando una fortificación en piedra, justo después de las escenas de la doble batalla de Nicopolis ad Istrum. En este sentido, las fuerzas seleccionadas del ejército desplegado en el interior de Dacia, así como los refuerzos procedentes de Panonia (CIL V, 6977 = ILS 1021; Fasti Prouinciales; Starr, 1960: 134; Bounegru y Zahariade, 1996: 101; Pitassi, 2010: 260-261) debieron de reunirse con Trajano en algún momento posterior a la derrota de los roxolanos y los dacios en el doble encuentro mencionado, transportadas a bordo de las naves de las classes romanas. Aunque algunos autores consideran la posibilidad de que la escena XXXIX de la Columna esté representando la fundación y construcción de Nicopolis ad Istrum (Stefan, 2005: 560; Depeyrot, 2008: 66-67; Oltean, 2015: 108), desde nuestro punto de vista resulta mucho más razonable atribuir esta escena a las reparaciones ejecutadas en fuertes romanos de la mitad occidental de Mesia Inferior (como Nouae o quizás Durostorum) asediados y/o ocupados por los dacios antes de su evacuación: la fundación y construcción de una nueva ciudad no constituiría ninguna prioridad mientras la seguridad de Mesia Inferior siguiera seriamente comprometida.

64 Siendo en el transcurso de estas operaciones cuando Q. Glitio Atilio Agrícola, al mando de las naves de la classis Flauia Pannonica, pudo seguramente obtener la corona classica (CIL V, $6977=$ ILS 1021). Es posible que L. Licinio Sura (CIL VI, 1444 = AE 2000, 135), D. Terencio Escauriano (CIL XII, 3169 = AE 1982, 678) o G. Cilnio Próculo (CIL XI, $1833=$ IDRE 1, $128=$ AE 1926, 123 = AE 1987, 392) consiguieran también sus respectivas coronae classicae en el contexto de esta necesaria ofensiva naval para recuperar el control del curso bajo del Danubio.

65 Escena XL de la Columna Trajana; metopas del Tropaeum Traiani; Henderson, 1968: 262; MacKendric, 1975: 80; Richmond, 1982: 43-53; Coulston, 1988: 359-360; Opreanu, 2000: 391; Stefan, 2005: 563-568; Opreanu, 2006: 116; Ardevan y Zerbini, 2007: 25-26; Depeyrot, 2008: 68-71; Oltean, 2015: 109-111; Zerbini, 2015: 51; Soria Molina, 2016: 246.

66 Metopas I-VII del Tropaeum Traiani; Alexandrescu Vianu, 2006: 217-219.

67 Metopas X-XXVII, XXXI, del Tropaeum Traiani; Alexandrescu Vianu, 2006: 217-219.

68 Metopas XXXV y XL-XLIII del Tropaeum Traiani; Alexandrescu Vianu, 2006: 217-219.

69 La escena XLI de la Columna Trajana muestra al ejército de la entente dácica replegándose apresuradamente, perseguido de cerca por las victoriosas fuerzas romanas. Posteriormente, la escena XLIII presenta a un elevado número de dacios, algunos de ellos pertenecientes a categoría de los pileati, capturados y recluidos como prisioneros por los romanos. Las almenas del Tropaeum Traiani, por su parte, muestran también a un elevado número de prisioneros dacios, bastarnos y sármatas roxolanos. En este sentido, es probable que, al ser alcanzados o verse atrapados en Mesia Inferior (tras resultar derrotada su armada en el Danubio y, en consecuencia, cortados los puntos de cruce previstos para la retirada al Norte), varios contingentes supervivientes del ejército invasor fueran tomados como prisioneros. En este sentido véase: Lepper y Frere, 1988: 89-90; Depeyrot, 2008: 74; Oltean, 2015: 109-110. 
de repliegue al norte del río, y cobrándose nuevas victorias sobre eventuales grupos de naves de guerra enemigas que opusieran resistencia ${ }^{70}$. Es igualmente posible que, aprovechando el desastre sufrido por los dacios y sus aliados, Trajano lanzara una breve expedición punitiva sobre Peuce, con la intención de asegurarse de que los bastarnos peucinos no volverían a colaborar en ningún asalto sobre Mesia Inferior ${ }^{71}$. Actuando en solitario o con apoyo de la armada bosforana, las classes romanas tenían ahora, además, vía libre para acceder a la costa noroccidental del Mar Negro y remontar los afluentes del bajo Danubio, amenazando directamente intereses roxolanos y bastarnos en la región mediante incursiones navales o anfibias destinadas a destruir el poder naval de la entente dácica en todos sus ámbitos.

La llegada del invierno puso fin a las operaciones militares activas, imponiendo una tregua obligada en todos los frentes que, en Mesia Inferior, fue aprovechada para reconstruir y reorganizar las defensas de la provincia con el objetivo de evitar futuros ataques, si bien las pérdidas sufridas por parte de la entente dácica en estos encuentros, así como otras circunstancias ${ }^{72}$, hicieron inviables ulteriores ofensivas de este tipo.

\section{CONCLUSIONES}

La gravísima derrota sufrida por la entente dácica en Mesia Inferior desgastó seriamente los recursos de la misma sin saldarse con ningún revés destacable de los progresos hechos por el ejército romano en suelo dacio durante el año precedente. Decébalo y sus aliados perdieron la iniciativa en el conflicto, forzados a mantenerse a la defensiva ante la imposibilidad de reunir recursos suficientes para volver a lanzar una ofensiva de entidad destacable sin correr riesgos inasumibles, como debilitar en exceso las defensas del entorno de Sarmizegetusa Regia, capital del reino, frente al inminente ataque romano previsto para la primavera del año $102 \mathrm{~d}$. C.73

De todos los miembros de la entente, el Estado dacio fue el más perjudicado por esta situación, siendo sus propios centros de poder los que se encontraban amenazados sin opción a recibir ayuda significativa por parte unos aliados que tenían frentes propios que atender ${ }^{74}$. Las posibilidades de evitar una derrota completa en la guerra para Dacia, por lo tanto, dependían de conseguir obstaculizar y retrasar todo lo posible el progreso de las fuerzas romanas en su territorio, con la esperanza de conseguir unas circunstancias favorables para un contraataque que le permitiera forzar un acuerdo lo menos perjudicial para sus intereses como fuese posible ${ }^{75}$.

70 CIL V, 6977 = ILS 1021; CIL VI, 1444 = AE 2000, 135; CIL XII, 3169 = AE 1982, 678; CIL XI, $1833=$ IDRE 1, $128=\mathrm{AE} 1926,123=\mathrm{AE} 1987,392$.

71 Operación consagrada fundamentalmente a constituir una masacre calculada, intencional y preventiva de las poblaciones de bárbaros allí asentadas, y no tanto una ocupación estable de la isla. La derrota sufrida por los bastarnos y sus aliados suponía una oportunidad excelente para neutralizar a los bastarnos peucinos como amenaza que difícilmente pudo ser desaprovechada por Trajano en el contexto de la campaña en Mesia Inferior de $101 \mathrm{~d}$. C.

72 La probable apertura de un frente en las estepas pónticas y la vecindad de Olbia por parte de los sármatas aorsos y el reino del Bósforo en calidad de aliados y cliente de Roma respectivamente (CIL XIV, 3608; Anokhin, 370, 395, 399, 411 y 488; Tácito, Ann., XII. 15-18; Plinio el Joven, Epist., X.63 y 67; Mielczarek, 1999: 16, 28-29, 79-80 y 100; Brzezinski y Mielczarek, 2002: 7-8; Lebedynsky, 2002: 42; Sarnowski, 2006: 85-92; Batty, 2007: 432; Lebedynsky, 2010: 10; Soria Molina, 2016: 256-258) ya antes de 101 d. C. (Dión de Prusa, Or., XXXVI. 15-16).

73 Soria Molina, 2016: 247-256.

74 Los sármatas roxolanos y los bastarnos, por ejemplo, tuvieron que hacer frente al ataque lanzado sobre su territorio y las principales rutas de comunicación que tenían con el Estado dacio por parte de M. Laberio Máximo y aliados nororientales del Imperio romano (el reino del Bósforo y los sármatas aorsos). Al respecto: Soria Molina, 2016: 252-260.

75 Aunque Decébalo no podía a aspirar a lograr una paz tan favorable como la firmada en $89 \mathrm{~d}$. C. con Domiciano (Plinio el Joven, Panegyricus, 11.5; 12. 2; 16. 3; Casio Dión, LXVII. 7. 2-4; Orosio, Hist. ad. Paganos, VII. 10. 3-4), su objetivo primordial en la primavera de $102 \mathrm{~d}$. C. era minimizar la posibilidad de que la guerra se saldara con una desarticulación total del Estado dacio y la alianza formada a su alrededor (Soria Molina, 2016: 260-268). 
Semejante realidad nunca se materializó y, aunque la paz impuesta finalmente al Estado dacio en 102 d. C. no supuso su destrucción, sí que sentenció su destino a corto plazo, abocándolo a un último y previsto conflicto con Roma en 105-106 d. C. que culminó en su anexión total al Imperio.

El significado de la derrota sufrida por la entente dácica a manos de Trajano en Mesia en el verano-otoño de $101 \mathrm{~d}$. C., sin embargo, trasciende el de su contribución decisiva a allanar la senda para la conquista romana de Dacia, única solución viable para el problema que esta había implicado para el poder romano en la Europa danubiana y oriental desde 69 d. C.: constituyó el simbólico capítulo final de las ambiciones expansionistas que el Estado dacio había mostrado desde tiempos de Burebista por el dominio del espacio danubiano, proceso que le había llevado a una colisión directa con los intereses romanos en la región y, por lo tanto, a impulsar y justificar en última instancia, desde el punto de vista del Imperio romano, su invasión, conquista y desarticulación total como entidad definida e independiente ${ }^{76}$.

76 Daicoviciu, 1984: 151-161; Lepper y Frere, 1988: 278 y 282; Mangas, 2003: 154-156; Stefan, 2005: 532-539; Oltean, 2015: 70-72; Zerbini, 2015: 39-40; Soria Molina, 2016: 221-225. 


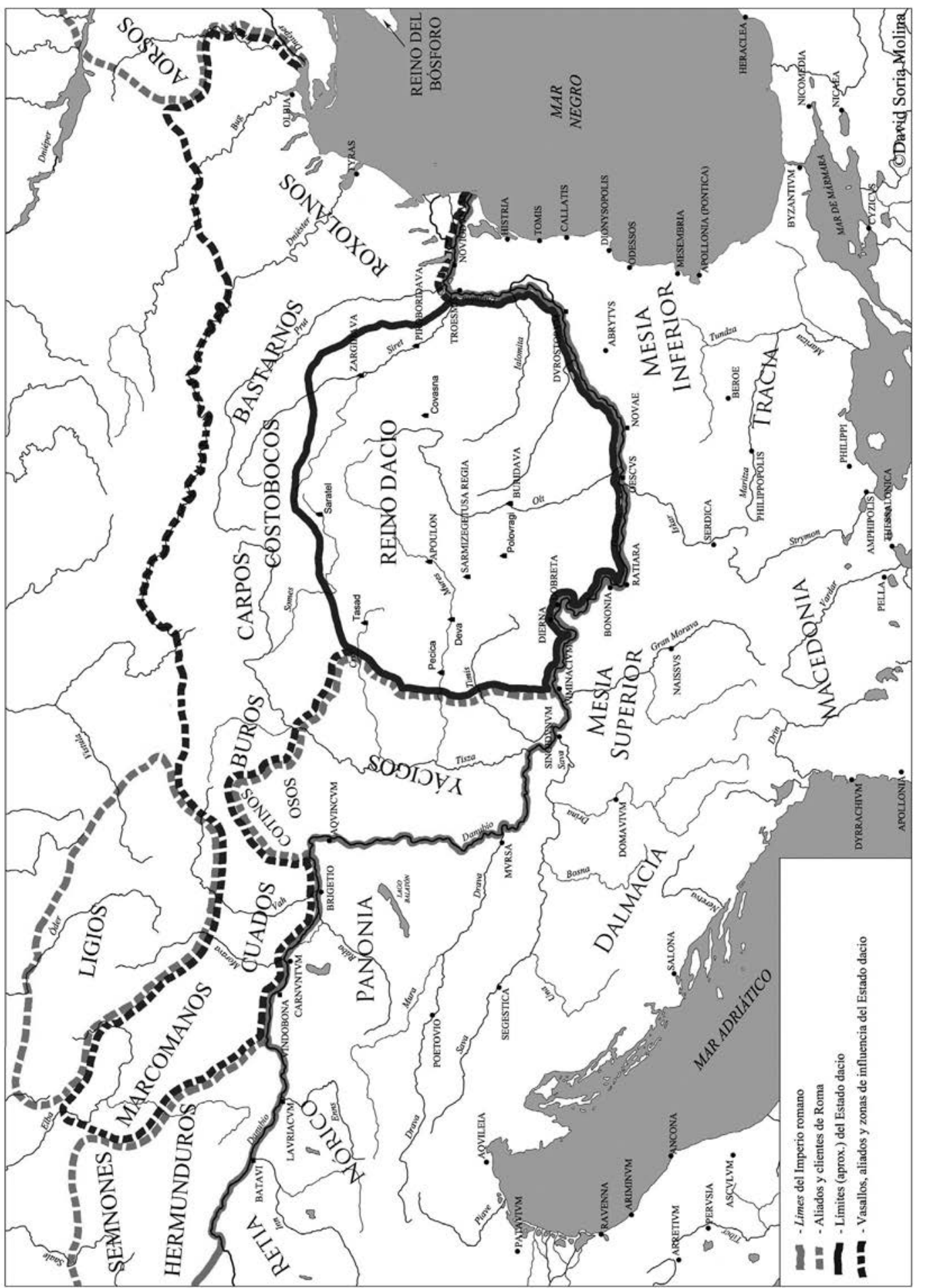

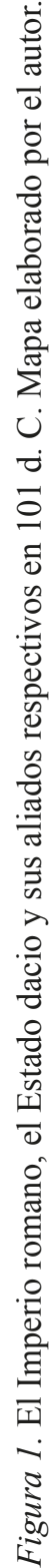




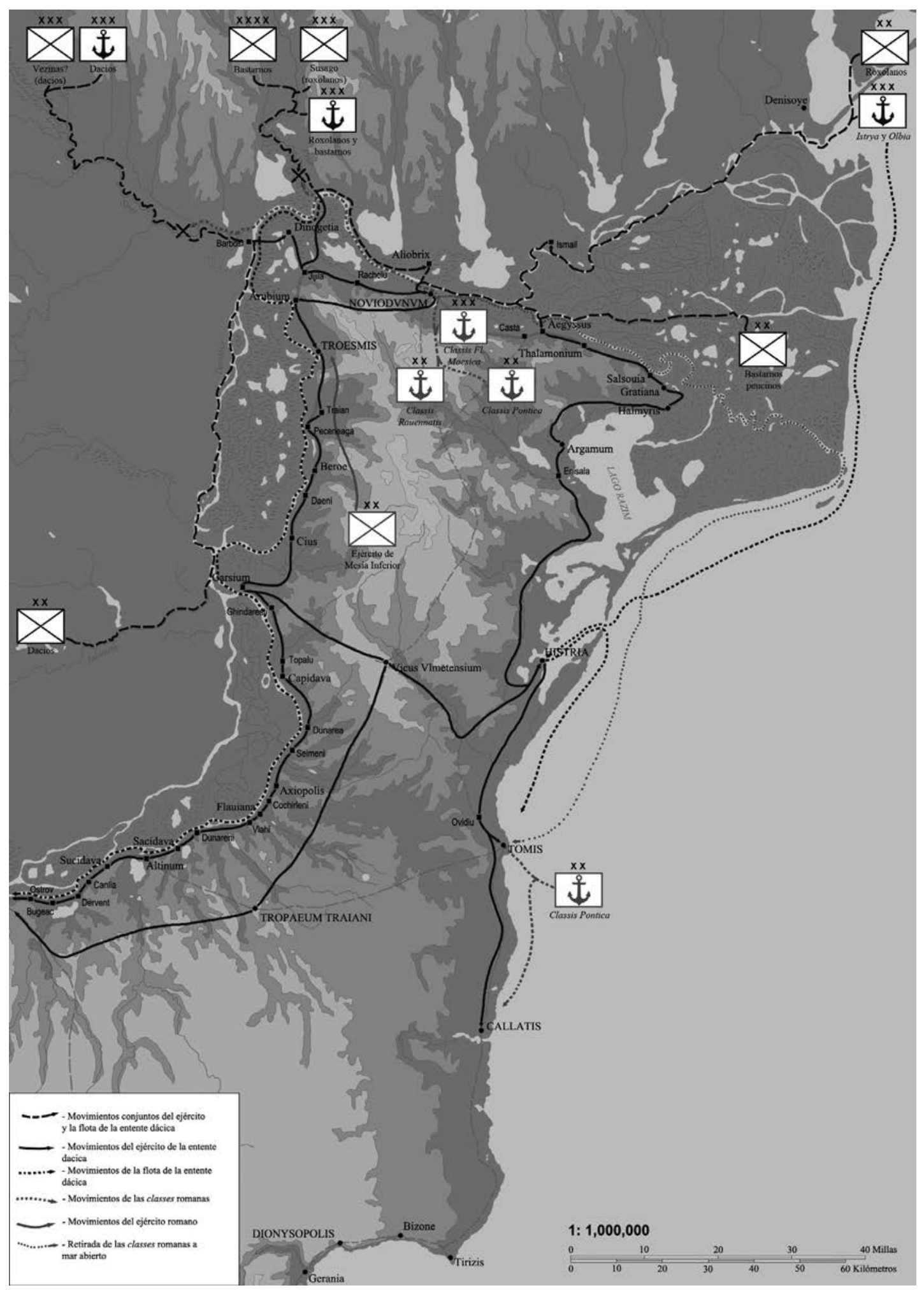

Figura 2. Invasión dácica de Mesia Inferior en el verano-otoño de 101 d. C. Mapa elaborado por el autor. 


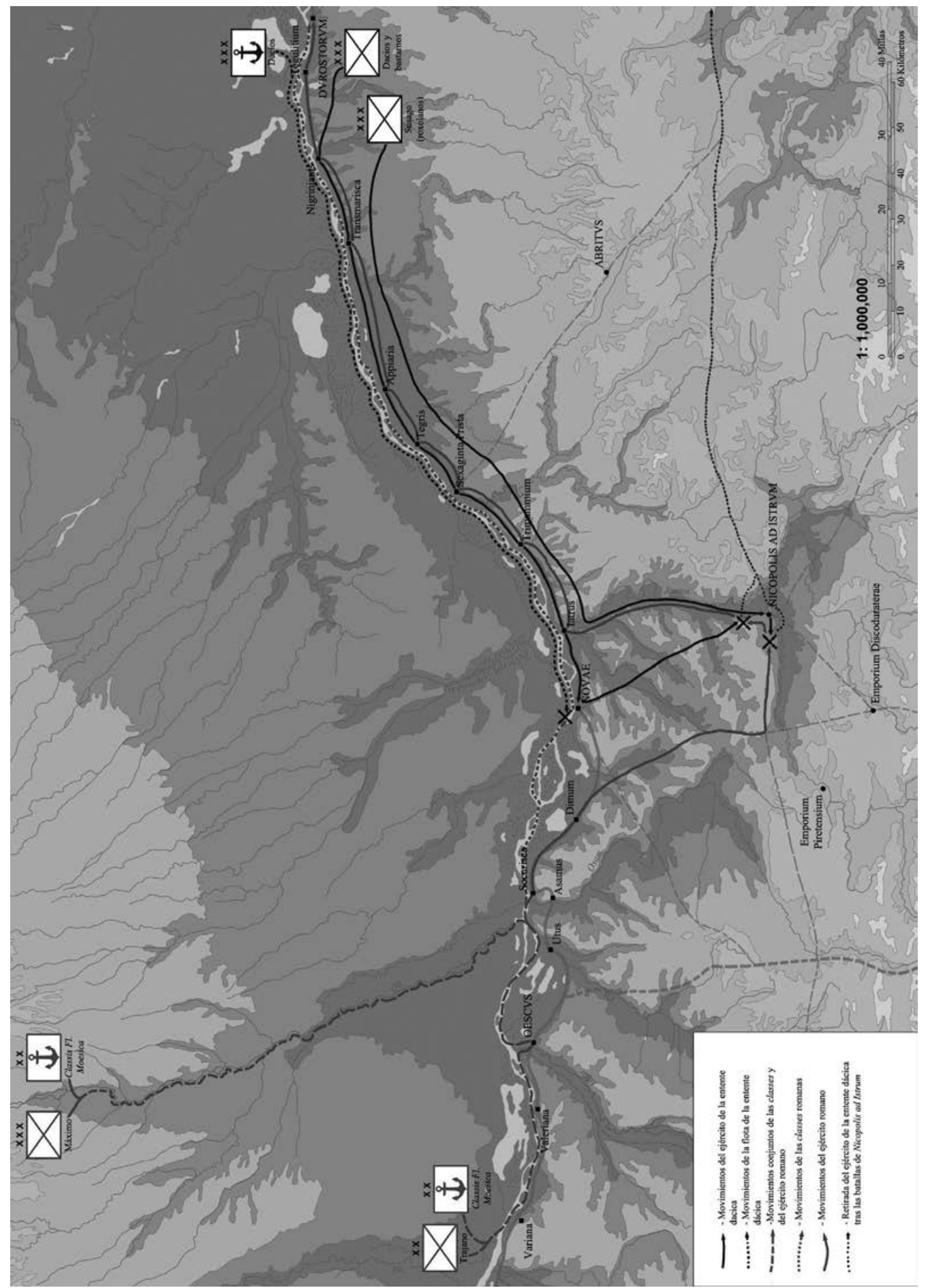

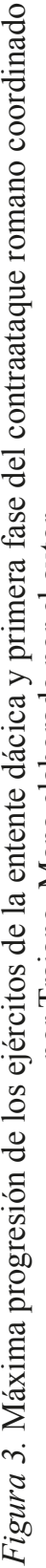

Gladius, XXXVIII (2018), pp. 67-87. ISSN: 0436-029X. https://doi.org/10.3989/gladius.2018.05 


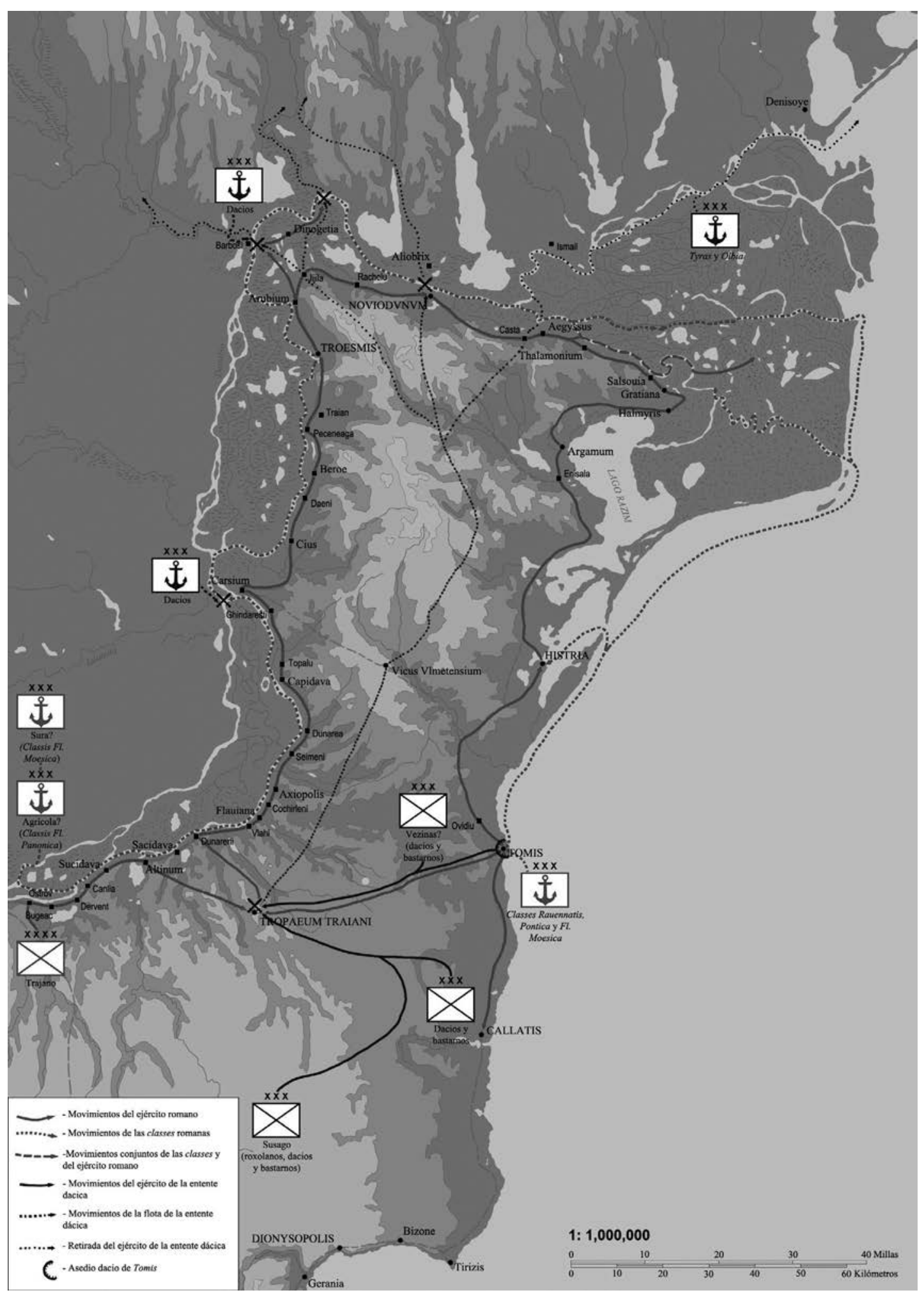

Figura 4. Segunda fase del contraataque romano en Mesia Inferior y derrota de las fuerzas de la entente dácica en la provincia. Mapa laborado por el autor. 


\section{BIBLIOGRAFÍA}

Alexandrescu-Vianu, M. (2006): «La propagande impériale aux frontières de l'Empire Romain: Tropaeum Traiani». Dacia, 50: 207-234.

Ardevan, R. y Zerbini, L. (2007): La Dacia romana. Catanzaro, Rubbettino.

Austin, N. J. E. y Rankov, B. (1995): Exploratio: Military and Political Intelligence in the Roman World. Londres, Routledge.

Batty, R. (2007): Rome and the Nomads: the Pontic-Danubian Realm in Antiquity. Oxford, Oxford University Press.

Bennett, J. (1997): Trajan, Optimus Princeps: a Life and Times. Londres, Routledge.

Blázquez Martínez, J. M. (2005): «Las res gestae de Trajano militar. Las guerras dácicas». Aquila Legionis, 6: 19-55.

Bounegru, O. y Zahariade, M. (1996): Les forces navales du Bas Danube et la Mer Noire aux Ier-VIe siècles. Oxford, Oxbow Books.

Brzezinski, R. y Mielczarek, M. (2002): The Sarmatians 600 BC-AD 450. Oxford, Osprey Publishing.

Carbó García, J. R. (2007): «Esclavitud y diplomacia en la carta LXXIV de Plinio el Joven: ¿sumisión o resistencia?». SHHA, 25: 291-304.

Coulston, J. C. N. (1988): Trajan's Column: The Sculpting and Relief content of a Roman propaganda monument. Newcastle Upon Tyne, Newcastle University Library.

Crişan, I. H. (1978): Burebista and his Time. Bucarest, Bibliotheca Historica Romaniae.

D’Amato, R. (2009): Imperial Roman Naval Forces 31BC-AD 500. Oxford, Osprey Publishing.

Daicoviciu, H. (1984): Portraits daciques. Bucarest, Editions Militaires.

Daicoviciu, H. y Trynkowski, J. (1970): «Les rois daces de Burébista à Décébale». Dacia, 14: 159-166.

Depeyrot, G. (2008): Légions romaines en campagne. La colonne Trajane. París, Errance.

Glodariu, I. (2000): «La zone de Sarmizegetusa Regia et les guerres de Trajan», SAA, VII: 363-376.

Henderson, B. W. (1968): Five Roman Emperors. Vespasian - Titus - Domitian - Nerva - Trajan A.D. 69-117. Roma, L'Erma di Bretschneider.

Kagan, K. (2006): «Redefining Roman Grand Strategy». The Journal of Military History, 70 (2): 333-362.

Lebedynsky, I. (2002): Les Sarmates. Amazones et lanciers cuirassés entre Oural et Danube VII siècle av. J.-C. - VI siècle apr. J.-C. París, Errance.

Lebedynsky, I. (2010): Sarmates et Alains face à Rome, $I^{e r}$-VI siècles. París, Errance.

Lepper, F. y Frere, S. (1988): Trajan's Column. A new edition of the Cichorius plates. Introduction, Commentary and Notes. Gloucester, Alan Sutton.

MacKendrick, P. (1975): The Dacian Stones Speak. Chapell Hill, University of North Carolina Press.

Mangas, J. (2003): «Trajano y las fronteras del Imperio», J. González (coord.), Trajano, óptimo príncipe. De Itálica a la corte de los Césares. Sevilla, Fundación El Monte: 141-171.

Mattern, S. P. (1999): Rome and the Enemy. Imperial Strategy in the Principate. Berkeley-Londres, University of California Press.

Mattern, S. P. (2012): «Contrainsurgencia y los enemigos de Roma», V. D. Hanson (ed.), El arte de la guerra en el mundo antiguo. De las guerras persas a la caída de Roma. Barcelona, Crítica: 165-184.

Matyszak, P. (2005): Los enemigos de Roma. Madrid, Oberón.

Mielczarek, M. (1999): The army of the Bosporan Kingdom. Łódź, Oficyna Naukowa MS.

Oltean, R. (2015): Dacia. La conquista romana. Volumen I : Sarmizegetusa. Madrid, Desperta Ferro.

Opreanu, C. (2000): «The Consequences of the First Dacian-Rumanian War (101-102). A new Point of View», J. González (ed.), Trajano Emperador de Roma. Roma, Saggi di Storia Antica: 389-401.

Opreanu, C. (2006): «Bellum Dacicum Traiani». Dacia, 50: 115-120.

Pitassi, M. (2010): The Navies of Rome. Woodbridge, Boydell Press.

Pogorzelski, R. (2012): Die Traianssäule in Rom. Dokumentation eines Krieges in Farbe. Mainz, Nünnerich-Asmus.

Reddé, M. (1986): Mare Nostrum. Les infrastructures, le dispositive et l'histoire de la marine militaire sous l'Empire romain. Roma, École Française de Rome.

Richmond, I. A. (1982): Trajan's Army on Trajan's Column. Londres, Hassall.

Rodríguez González, J. (2003): Historia de las legiones romanas. Madrid: Almena.

Rossi, L. (1971): Trajan's Column and the Dacian Wars. Londres, Thames and Hudson. 
Sarnowski, T. (2006): «The Phantom Squadron of the Ravennate Fleet on the Black Sea in the $1^{\text {st }}$ Century AD». ZPE, 157: 256-260.

Soria Molina, D. (2014): «La expansión del Reino dacio bajo Burebista, siglo I a. C.». ETF, Serie II Historia Antigua, 27: 137-152.

Soria Molina, D. (2016): Bellum Dacicum. Geopolítica, estrategia y conflicto en el Danubio bajo Domiciano y Trajano (85-106 d. C.). Madrid-Salamanca, Signifer Libros.

Soria Molina, D. (2017): «Cuados, marcomanos y la confederación sueva en las guerras dácicas de Domiciano y Trajano». SHHA, 35: 95-117.

Soria Molina, D. (2018): «Dacia Deserta: Migraciones, deportaciones, despoblamiento y colonización durante las guerras dácicas de Trajano (101-102 d. C.)», F. Puell de la Villa y D. García Hernán (eds.), Los efectos de la guerra. Desplazamientos de población a lo largo de la historia. Madrid, Instituto Universitario general Gutiérrez Mellado-UNED: 83-104.

Southern, P. (1997): Domitian. Tragic Tyrant. Londres y Nueva York, Routledge.

Speidel, M. P. (2004): Ancient Germanic Warriors: warrior styles from Trajan's column to Icelandic sagas. Londres y Nueva York, Routledge.

Starr, C. G. (1960): The Roman Imperial Navy 31BC - A.D. 324. Cambridge, Heffer \& Sons Ltd.

Stefan, A. S. (2005): Les guerres daciques de Domitien et de Trajan. Architecture militaire, topographie, images et histoire. Roma, École Française de Rome.

Strobel, K. (1984): Untersuchungen zu den Dakerkriegen Trajans. Studien zu Geschichte des mittleren und unteren Donauraumes in der Höhen Kaiserzeit. Bonn.

Vădan, P. I. (2007-2008): «Patterns of Continuity in Geto-Dacian Foreign Policy under Burebista». Hirundo, 6: 69-86.

Wheeler, E. L. (2010): «Rome's Dacian Wars: Domitian, Trajan, and Strategy on the Danube, Part 1». Journal of Military History, 74 (4): 1185-1227.

Wheeler, E. L. (2011): «Rome's Dacian Wars: Domitian, Trajan, and Strategy on the Danube, Part 2». Journal of Military History, 75 (1): 191-219.

Wilkes, J. J. (1983): «Romans, Dacians and Sarmatians in the First and Early Second Centuries», B. Hartley y J. Wacher (eds.), Rome and her Nothern Provinces: Papers Presented to S. Frere. Gloucester, Alan Sutton.

Wilkes, J. J. (2005): «The Roman Danube: An Archaeological Survey». JRS, 95: 124-225.

Zerbini, L. (2015): Le guerre daciche. Bolonia, Il Mulino.

Recibido: 18-01-2018

Aceptado: 27-08-2018 